\title{
Comparative genomics for mycobacterial peptidoglycan remodelling enzymes reveals extensive genetic multiplicity
}

\author{
Edith Erika Machowski, Sibusiso Senzani, Christopher Ealand and Bavesh Davandra Kana*
}

\begin{abstract}
Background: Mycobacteria comprise diverse species including non-pathogenic, environmental organisms, animal disease agents and human pathogens, notably Mycobacterium tuberculosis. Considering that the mycobacterial cell wall constitutes a significant barrier to drug penetration, the aim of this study was to conduct a comparative genomics analysis of the repertoire of enzymes involved in peptidoglycan $(P G)$ remodelling to determine the potential of exploiting this area of bacterial metabolism for the discovery of new drug targets.

Results: We conducted an in silico analysis of 19 mycobacterial species/clinical strains for the presence of genes encoding resuscitation promoting factors (Rpfs), penicillin binding proteins, endopeptidases, L,D-transpeptidases and $\mathrm{N}$-acetylmuramoyl-L-alanine amidases. Our analysis reveals extensive genetic multiplicity, allowing for classification of mycobacterial species into three main categories, primarily based on their rpf gene complement. These include the M. tuberculosis Complex (MTBC), other pathogenic mycobacteria and environmental species. The complement of these genes within the MTBC and other mycobacterial pathogens is highly conserved. In contrast, environmental strains display significant genetic expansion in most of these gene families. Mycobacterium leprae retains more than one functional gene from each enzyme family, underscoring the importance of genetic multiplicity for PG remodelling. Notably, the highest degree of conservation is observed for $\mathrm{N}$-acetylmuramoyl-L-alanine amidases suggesting that these enzymes are essential for growth and survival.
\end{abstract}

Conclusion: PG remodelling enzymes in a range of mycobacterial species are associated with extensive genetic multiplicity, suggesting functional diversification within these families of enzymes to allow organisms to adapt.

Keywords: Peptidoglycan, Transglycosylases, Amidases, D,D-carboxypeptidases, Transpeptidases, Endopeptidases

\section{Background}

Bacteria inhabit every environment on earth with a resilience that is central to their survival and consequently, they continue to serve as a major source of human disease. A critical factor, which has been central to the success of these organisms, is the diversity entrenched within their cell walls, which serves as a major barrier to drug treatment. The mycobacterial cell wall is an incredibly complex structure, with multiple layers that collectively constitute a waxy, durable coat around the cell, which serves as the major permeability barrier to drug action [1-4]. Considering this, the cell wall and related

\footnotetext{
* Correspondence: bavesh.kana@nhls.ac.za

DST/NRF Centre of Excellence for Biomedical TB Research, Faculty of Health Sciences, University of the Witwatersrand, National Health Laboratory Service,
} P.O. Box 1038, Johannesburg 2000, South Africa components are attractive for the mining of new drug targets, and remain relatively unexploited for drug discovery in the case of certain bacterial pathogens $[2,5,6]$. Peptidoglycan (PG or the murein sacculus) is a rigid layer that constricts the cell membrane and the cell within, providing mechanical stability to counteract imbalances of cytoplasmic turgour pressure, and plays an important role in determining cell size and shape [7-10]. Mycobacteria possess a highly complex additional lipid rich outer membrane, with different constituents anchored either directly to the cell membrane or to the PG [6,11]. Arabinoglactan (AG), a structure unique to actinomycetes, is bound externally to an $\mathrm{N}$-acetyl muramic acid (NAM) moiety of the PG [3,12]. In mycobacteria, a certain proportion of the muramic acid is $\mathrm{N}$-glycolylated [13] through the activity of $\mathrm{NamH}$, a UDP- $N$-acetylmuramic 
acid hydroxylase [14]. This modification results in altered tumour necrosis factor $\alpha$ production $[15,16]$ however, abrogation of $\mathrm{NamH}$ activity does not lead to decreased virulence in mice [16].

This serves as an anchor for further lipid rich cell wall components, either by covalent attachment to the mycolic acid layer or through non-covalent interactions [trehalose dimycolate (TDM); phthiocerol dimycocerosate (PDIM); phenolic glycolipids (PGL)] [3,11,12]. PG consists of repeated alternating sugars $N$-acetyl glucosamine (NAG) and NA/GM (muramic acid with or without the glycolyl modification), which are linked to a pentapeptide side chain [7-9,17], Figure 1. The crosslinking of these subunits lead to a lattice-like structure around the cell.

The PG in bacterial cell walls is an incredibly dynamic structure that requires constant expansion and remodelling during growth to accommodate the insertion of new PG subunits, secretion apparatus, flagellae etc. $[9,10]$. During cell division, pre-septal PG synthesis and subsequent degradation of the septum is critical to daughter cell separation; consequently these processes are carefully regulated [7]. In this regard, there is a diversity of enzymes involved in cross-linking, degradation and remodelling of PG, which are illustrated in Figure 1. A ubiquitous feature in bacteria is the genetic multiplicity associated with these functions, which presumably contributes to the ability of different organisms to adapt under varying environmental conditions $[7,9,10]$. In the case of Mycobacterium tuberculosis, the causative agent of tuberculosis, there is a dire need for new drugs with novel modes of action. The increased prevalence of drug resistant strains has raised concerns regarding the sustainability of the current treatment regimen. To address this, several aspects of mycobacterial metabolism are being assessed for potential new drug targets [18]. The genetic redundancy associated with PG biosynthesis together with the reliance on robust bacterial growth to achieve significant drug target vulnerability, has hampered drug development initiatives that target the cell wall [19]. For other bacterial pathogens, PG has been successfully used as an antibiotic target in the past, as evidenced by the widespread use of $\beta$-lactam antibiotics among others, the biosynthesis and degradation of this macromolecule in mycobacteria is meritorious of further investigation.

In this study, we undertake a comprehensive analysis of the genomic repertoire of PG remodelling enzymes in various pathogenic and environmental mycobacteria to determine the level of genetic multiplicity/redundancy and degree of conservation. We focus on those enzymes involved in cross-linking and remodelling of the PG in the periplasmic compartment, including: resuscitation promoting factors (Rpfs), penicillin binding proteins (PBPs), transpeptidases, endopeptidases, and $\mathrm{N}$-acetylmuramoyl-
L-alanine amidases. Our data reveal extensive genetic multiplicity for the 19 strains analysed in this study, which allowed grouping of strains into three families based on their complement of PG remodelling enzymes, including the $\mathrm{MTBC}$, other pathogenic mycobacteria and nonpathogenic environmental organisms.

\section{Results and Discussion}

The comparative genomics analysis for PG remodelling enzymes in mycobacterial species obtained from this study is summarised in Table 1 . We analysed 19 distinct species/strains: Six of these belong to the MTBC, six are classified as other pathogenic bacteria [three of which belong to the Mycobacterium avium complex (MAC)] and six environmental species including Mycobacterium smegmatis. Mycobacterium leprae is listed separately due to its substantially reduced genome which emerges as an outlier in the analysis.

\section{Resuscitation promoting factors (lytic transglycosylases)}

Of all the enzymes identified in this study, the Rpf family is the most extensively studied. This group of enzymes are of particular interest due to demonstrated importance for reactivation from dormancy and essentiality for growth in Micrococcus luteus [22,23]. Whilst Mi. luteus encodes a single, essential rpf gene, mycobacteria encode a multiplicity of $r p f$ homologues and those present in $M$. tuberculosis, designated as rpfA-rpfE, encode closely related proteins all of which retain the $\mathrm{Rpf}$ domain [24-26], Figure 2. These have been the subject of intense study due to the potential role they may play in reactivation disease in individuals that harbour latent TB infection [25,27-31]. In this regard, the five $r p f$ genes present in $M$. tuberculosis are collectively dispensable for growth but are differentially required for reactivation from an in vitro model of non-culturability [32,33]. Furthermore, the Rpfs are combinatorially required to establish TB infection and for reactivation from chronic infection in mice [32-35]. For additional information, the reader is referred to several extensive reviews on this topic [25,27,28,36-38].

Rpfs are classified as lytic transglycosylases (LTs) based on sequence conservation and three-dimensional protein structure [29,39-41]. LTs cleave the $ß-1,4$-glycosidic bonds between the NAG-NA/GM sugar subunits, Figure 1, and their activity is required for insertion of new PG units and expansion of the glycan backbone [9]. In mycobacteria RpfB contains a lysozyme-like, transglycosylase-like PFAM domain, and consequently this group of enzymes are predicted to cleave the glycan backbone of PG [39-41]. Direct evidence for this is lacking and moreover, the mechanism through which Rpf-mediated cleavage of PG results in growth stimulation remains unknown. The repertoire of rpf genes is highly conserved in the MTBC; in contrast, 




Figure 1 PG units and chemical bonds associated with remodelling enzyme activities. At the top and bottom of the figure are shown the NAG-NA/GM sugar backbone in anti-parallel orientation. The NAM residues are designated as NA/GM to correspond to the N-glycolylation of muramic acid in mycobacteria. Enzymatic activities are indicated by arrows: Rpfs [yellow], PBPs [orange], endopeptidases [pink], L,D-transpeptidases [green] and amidases [blue], which are related to the corresponding colours in Table 1. Amino acid residues in the stem peptide are shown in black text. Pentapeptide stems are attached to the Carbon at position 3 of the NAM ring. Transglycosylase activities of Rpfs and the Pon domain indicate their B-1,4-glycosidic bond substrate. Synthetic enzyme activities are shown on the left, that is those that generate bonds cross-linking the pentapeptides on opposing stems, by Pon and Pbp proteins at positions 4,3 (L-Ala to meso-DAP) or Ldt proteins at positions 3,3 (meso-DAP to meso-DAP). The hydrolytic enzyme activities are shown to the right. These include the amidases, the RipA endopeptidases and the DD-CPase (DacB) acting on the pentapeptide stem (pre- or post-crosslinking).

other pathogenic mycobacteria lack $r p f D$, including $M$. leprae, Table 1. Based on the distribution of $r p f C$ and $r p f D$, we categorize the 19 strains analysed in this study into the MTBC (which retains all five rpf homologues present in $M$. tuberculosis), other pathogenic mycobacteria (which lack $r p f D$ ) and environmental strains (which lack both $r p f(C$ and $r p f D$ ). This classification is supported by phylogenetics analysis which confirms these clusters and duplication/loss of genes, Additional file 1: Figure S1. Recently, it has been shown that the Rpfs can serve as potent antigens [42] and Rpf-directed host immune responses allow for detection of TB in latently infected individuals [43]. It is noteworthy that strains lacking different combinations of $r p f$ genes confer significant protective efficacy when used as vaccine strains in mice [44]. Hence, any variation in rpf gene complement between pathogenic mycobacteria may have significant consequences for broadly protective effects of future Rpf-based vaccines.

The environmental species retain three $r p f$ genes [rpfA, rpfB (duplicated in Mycobacterium sp. JLS, Mycobacterium 
Table 1 Genetic complement for PG remodelling enzymes in 19 mycobacterial species

\begin{tabular}{|c|c|c|c|c|c|c|c|c|c|c|c|c|c|c|c|c|c|c|c|}
\hline & \multicolumn{6}{|c|}{ MTB complex } & \multicolumn{6}{|c|}{ Other mycobacterial pathogens } & \multicolumn{6}{|c|}{ Environmental mycobacterial species } & \multirow[b]{2}{*}{$\begin{array}{l}\text { M. } \\
\text { leprae } \\
\text { TN }\end{array}$} \\
\hline & $\begin{array}{c}. \\
\text { tuberculosis } \\
\text { H37Rv }\end{array}$ & $\begin{array}{c}\text { M. } \\
\text { tuberculosis } \\
\text { H37Ra }\end{array}$ & $\begin{array}{c}M . \\
\text { tuberculosis } \\
\text { CDC1551 }\end{array}$ & $\begin{array}{c}M . \\
\text { africanum } \\
\text { GM041182 }\end{array}$ & $\begin{array}{l}\text { M. bovis } \\
\text { AF2122/97 }\end{array}$ & $\begin{array}{l}\text { M. bovis } \\
\text { BCG } \\
\text { Pasteur } \\
1173 P 2\end{array}$ & $\begin{array}{l}\text { M. avium } \\
104\end{array}$ & $\begin{array}{c}\text { M. avium } \\
\text { subsp. } \\
\text { paraTB } \\
K-10\end{array}$ & $\begin{array}{c}M . \\
\text { intracellulare } \\
\text { ATCC } 13950\end{array}$ & $\begin{array}{c}M . \\
\text { ulcerans } \\
A G Y 99\end{array}$ & $\begin{array}{c}M . \\
\text { marinum } \\
M\end{array}$ & $\begin{array}{c}M . \\
\text { abscessus } \\
\text { ATCC19977 }\end{array}$ & $\begin{array}{c}M . \\
\text { smegmatis } \\
\text { mc }^{2} 155\end{array}$ & $\begin{array}{c}M . \\
\text { vanbaalenii } \\
\text { PYR-1 }\end{array}$ & M. sp. MCS & M. sp. KMS & M. sp. JLS & $\begin{array}{l}\text { M. gilvum } \\
P Y R-G C K\end{array}$ & \\
\hline \multicolumn{20}{|c|}{ Resuscitation promoting factors } \\
\hline rpfA & Rv0867c & MRA_0874 & МТ0890 & MAF_08760 & Mb0891c & BCG_0919C & MAV_0996 & MAP0805c & OCU_08710 I & MUL_0283 & MMAR_4665 & MAB_0869c & MSMEG_5700 & Mvan_5049 & Mmcs_4479 & Mkms_4566 & Mjls_4862 & Mflv_1703 & ML2151 \\
\hline rpfB & Rv1009 & MRA_1018 & MT1038 & MAF_10190 & Mb1036 & BCG_1066 & MAV_1147 & MAP0974 & OCU_10320 & MUL_4651 & MMAR_4479 & MAB_1130 & MSMEG_5439 & Mvan_4801 & $\begin{array}{l}\text { Mmcs_4264 } \\
\text { Mmcs_1712 }\end{array}$ & $\begin{array}{l}\text { Mkms_4350 } \\
\text { Mkms_1758 }\end{array}$ & $\begin{array}{l}\text { Mils_4643 } \\
\text { Mjls_1689 }\end{array}$ & Mflv_1932 & ML0240 \\
\hline rpfC & Rv1884C & MRA_1895 & MT1932 & MAF_19060 & Mb1916c & BCG_1921C & MAV_2818 & MAP1607c & OCU_26380 I & MUL_2975 & MMAR_2772 & MAB_4080 & - & - & - & - & - & - & ML2030 \\
\hline$r p f D$ & Rv2389c & MRA_2413 & MT2458 & MAF_24030 & Mb2410c & BCG_2403C & - & - & - & - & - & - & - & - & - & - & - & - & - \\
\hline IPfE & Rv2450c & MRA_2476 & MT2526 & MAF_24670 & Mb2477c & BCG_2470c & MAV_1722 & MAP2273C & OCU_18020 I & MUL_3723 & MMAR_3776 & MAB_1597 & $\begin{array}{l}\text { MSMEG_4643/ } \\
\text { MSMEG_4640 }\end{array}$ & $\begin{array}{l}\text { Mvan_3962/ } \\
\text { Mvan_3961 } \\
\end{array}$ & $\begin{array}{l}\text { Mmcs_3564/ } \\
\text { Mmcs_3563 }\end{array}$ & $\begin{array}{l}\text { Mkms_3637/ } \\
\text { Mkms_3636 }\end{array}$ & $\begin{array}{l}\text { Mils_3569/ } \\
\text { Mjls_3568 } \\
\end{array}$ & $\begin{array}{l}\text { Mflv_2619/ } \\
\text { Mffl_2620 }\end{array}$ & - \\
\hline \multicolumn{20}{|c|}{ Penicillin binding proteins } \\
\hline ponA1 & Rv0050 & MRA_0053 & MT0056 & MAF_00500 & Mb0051 & BCG_0081 & MAV_0071 & MAP0064 & OCU_00670 I & MUL_0068 & MMAR_0069 & MAB_4901C & MSMEG_6900 & Mvan_6036 & Mmcs_5372 & Mkms_5461 & Mjls_5748 & Mflv_0871 & ML2688c \\
\hline ponA2 & Rv3682 & MRA_3717 & MT3784 & MAF_36900 & Mb3707 & BCG_3741 & MAV_0446 & MAP0392C & OCU_03970 & MUL_4257 & MMAR_5171 & MAB_0408c & $\begin{array}{l}\text { MSMEG_6201 } \\
\text { MSMEG_4384 }\end{array}$ & $\begin{array}{l}\text { Mvan_5442 } \\
\text { Mvan_1068 }\end{array}$ & $\begin{array}{l}\text { Mmcs_4825 } \\
\text { Mmcs_1483 }\end{array}$ & $\begin{array}{l}\text { Mkms_4911 } \\
\text { Mkms_1505 }\end{array}$ & $\begin{array}{l}\text { Mjls_5212 } \\
\text { Mjls_1480 }\end{array}$ & $\begin{array}{l}\text { Mflv_1365 } \\
\text { Mflv_5209 }\end{array}$ & ML2308 \\
\hline pbpA & Rv0016c & MRA_0018 & MT0019 & MAF_00160 & Mb0016c & BCG_0046C & MAV_0020 & MAP0019C & OCU_00180 I & MUL_0020 & MMAR_0018 & MAB_0035c & MSMEG_0031 & Mvan_0025 & Mmcs_0017 & Mkms_0025 & Mjls_0017 & Mflv_0810 & ML0018 \\
\hline$p b p B$ & Rv2163c & MRA_2178 & MT2221 & MAF_21760 & Mb2187c & BCG_2180C & MAV_2330 & MAP1903c & OCU_22960 & MUL_3508 & MMAR_3200 & MAB_2000 & MSMEG_4233 & Mvan_3529 & Mmcs_3262 & Mkms_3324 & Mjls_3273 & Mflv_2982 & ML0908 \\
\hline PBP-lipo & Rv2864c & MRA_2889 & MT2933 & MAF_28690 & Mb2889c & BCG_2886c & MAV_3723 & MAP2936C & OCU_35570 & MUL_2089 & MMAR_1840 & MAB_3167c & $\begin{array}{l}\text { MSMEG_2584 } \\
\text { MSMEG_6319 }\end{array}$ & $\begin{array}{l}\text { Mvan_2266 } \\
\text { Mva_4630 }\end{array}$ & $\begin{array}{l}\text { Mmcs_2047 } \\
\text { Mmcs_4955 }\end{array}$ & $\begin{array}{l}\text { Mkms_2093 } \\
\text { Mkms_5043 }\end{array}$ & $\begin{array}{l}\text { Mjls_2030 } \\
\text { Mjls_5336 }\end{array}$ & $\begin{array}{l}\text { Mflv_4076 } \\
\text { Mffl__2080 }\end{array}$ & ML1577c \\
\hline$d a c B 1$ & Rv3330 & MRA_3372 & МT3433 & MAF_33460 & Mb3363 & BCG_3400 & MAV_4305 & MAP3448 & OCU_41630 & MUL_1445 & MMAR_1192 & MAB_3681 & MSMEG_1661 & Mvan_1562 & Mmcs_1216 & Mkms_1233 & Mjls_1243 & Mflv_4869 & ML0691 \\
\hline dacB2 & Rv2911 & MRA_2936 & MT2979 & MAF_29150 & Mb2935 & BCG_2932 & MAV_3766 & MAP2979 & OCU_36070 & MUL_2045 & MMAR_1797 & MAB_3234 & $\begin{array}{l}\text { MSMEG_2433/ } \\
\text { MSMEG_2432 }\end{array}$ & $\begin{array}{l}\text { Mvan_2184/ } \\
\text { Mvan_2183 }\end{array}$ & $\begin{array}{l}\text { Mmcs_1962/ } \\
\text { Mmcs_1961 }\end{array}$ & $\begin{array}{l}\text { Mkms_2008/ } \\
\text { Mkms_2007 }\end{array}$ & $\begin{array}{l}\text { Mils_1942/ } \\
\text { Mjls_1941 }\end{array}$ & $\begin{array}{l}\text { Mflv_4179/ } \\
\text { Mffl__4180 }\end{array}$ & - \\
\hline Rv3627c & $R v 3627 c$ & MRA_3663 & MT3729 & MAF_36340 & Mb3651c & BCG_3685C & MAV_0529 & MAP0436 & OCU_04440 & MUL_4203 & MMAR_5127 & MAB_0519 & MSMEG_6113 & Mvan_5380 & Mmcs_4778 & Mkms_4864 & Mjls_5164 & Mflv_1409 & ML0211 \\
\hline MSMEG_1900 & - & - & - & - & - & - & - & - & - & - & - & MAB_2019 & MSMEG_1900 & Mvan_4520 & Mmcs_0342 & Mkms_0352 & Mjls_0331 & Mflv_2177 & - \\
\hline \multicolumn{20}{|c|}{ Endo-Peptidases } \\
\hline Rv0024 & Rv0024 & MRA_0027 & MT0027 & MAF_00240 & Mb0024 & BCG_0054 & MAV_0042 & MAP0036 & OCU_00360 & MUL_0042 & MMAR_0043 & - & - & - & - & - & - & - & - \\
\hline ripA & Rv1477 & MRA_1487 & MT1524 & MAF_15000 & Mb1513 & BCG_1539 & MAV_3301 & MAP1203 & OCU_31420 I & MUL_1486 & MMAR_2284 & MAB_2728c & MSMEG_3145 & $\begin{array}{l}\text { Mvan_3656 } \\
\text { Mvan_2747 }\end{array}$ & $\begin{array}{l}\text { Mmcs_1440 } \\
\text { Mmcs_2451 }\end{array}$ & $\begin{array}{l}\text { Mkms_5716 } \\
\text { Mkms_1458 } \\
\text { Mkms_2496 }\end{array}$ & $\begin{array}{l}\text { Mjls_2488 } \\
\text { Mjls_4564 } \\
\text { Mjls_4520 }\end{array}$ & $\begin{array}{l}\text { Mflv_5292 } \\
\text { Mflv_0895 } \\
\text { MAllf_2839 } \\
\text { Mfll__3663 }\end{array}$ & ML1812 \\
\hline ripB & Rv1478 & MRA_1488 & MT1525 & MAF_15010 & Mb1514 & BCG_1540 & MAV_3300 & MAP1204 & OCU_31410 & MUL_1487 & MMAR_2285 & MAB_2727c & MSMEG_3146 & $\begin{array}{l}\text { Mvan_2748 } \\
\text { Mvan_3652 }\end{array}$ & $\begin{array}{l}\text { Mmcs_2452 } \\
\text { Mmcs_1447 }\end{array}$ & $\begin{array}{l}\text { Mkms_2497 } \\
\text { Mkms_1465 } \\
\text { Mkms_5687 } \\
\text { Mkms_5720 }\end{array}$ & $\begin{array}{l}\text { Mjls_2 } 2489 \\
\text { Mijls_4472 } \\
\text { Mjls_ } 4557 \\
\text { Mijs_ } 4529\end{array}$ & $\begin{array}{l}\text { Mflv_5324 } \\
\text { Mfll_5288 } \\
\text { MAll__9002 } \\
\text { Mfll__2843 }\end{array}$ & ML1811 \\
\hline $\operatorname{ripD}$ & Rv1566c & MRA_1578 & MT1617 & MAF_15930 & Mb1593c & BCG_1619C & MAV_3208 & MAP1272C & OCU_30430 & MUL_1557 & MMAR_2381 & (MAB_2474) & (MSMEG_3477) & (Mvan_2970) & (Mmcs_2672) & (Mkms_2717) & (Mjls_2702) & (Mflv_3253) & ML1214 \\
\hline Rv2190c & Rv2190c & MRA_2205 & MT2245 & MAF_22010 & Mb2213c & BCG_2206c & MAV_2304 & MAP1928C & OCU_22720 & MUL_3545 & MMAR_3234 & MAB_1974 & MSMEG_4256 & $\begin{array}{l}\text { Mvan_3552 } \\
\text { Mvan_3713 }\end{array}$ & $\begin{array}{l}\text { Mmcs_3287 } \\
\text { Mmcs_1435 }\end{array}$ & $\begin{array}{l}\text { Mkms_3349 } \\
\text { Mkms_56661 } \\
\text { Mkms_1453 }\end{array}$ & $\begin{array}{l}\text { Mils_3298 } \\
\text { Milis_4528 } \\
\text { Mils_4570 }\end{array}$ & $\begin{array}{l}\text { Mflv_2959 } \\
\text { Mfll_55385 } \\
\text { Mfll_5350 } \\
\text { Mlli_2808 } \\
\text { Mfll__0888 }\end{array}$ & ML0885 \\
\hline \multicolumn{20}{|c|}{ L,D-transpeptidases } \\
\hline $1 d t_{M t 1}$ & Rv0116c & MRA_0123 & MT0125 & MAF_01170 & Mb0120c & BCG_0150C & MAV_5194 & MAР3520C & OCU_50160 I & MUL_4806 & MMAR_0316 & MAB_3165c & MSMEG_3528 & Mvan_3019 & Mmcs_2729 & Mkms_2773 & Mjls_2759 & Mflv_3298 & ML2664 \\
\hline $1 d t_{M+2}$ & Rv2518c & MRA_2545 & MT2594 & MAF_25330 & Mb2547c & BCG_2539C & MAV_1661 & MAP2322C & OCU_17500 I & MUL_3804 & MMAR_3872 & MAB_1530 & MSMEG_4745 & $\begin{array}{l}\text { Mvan_4102 } \\
\text { Mvan_3651 } \\
\text { Mvan_5854 }\end{array}$ & $\begin{array}{l}\text { Mmcs_1448 } \\
\text { Mmcs_3641 }\end{array}$ & $\begin{array}{l}\text { Mkms_5721 } \\
\text { Mkms_3714 } \\
\text { Mkms_1466 }\end{array}$ & $\begin{array}{l}\text { Mjls_3646 } \\
\text { Mjls_4532 } \\
\text { Mjls_4556 }\end{array}$ & $\begin{array}{l}\text { Mflv_2542 } \\
\text { Mllf_5287 } \\
\text { Mflv_2004 }\end{array}$ & ML0426 \\
\hline $1 d t_{M+3}$ & Rv1433 & MRA_1442 & MT1477 & MAF_14550 & Mb1468 & BCG_1494 & MAV_4834 & MAР $3812 C$ & OCU_47330 & - & MMAR_3552 & MAB_4775 & MSMEG_0674 & - & - & - & Mjls_4515 & Mflv_1397 & ML0569 \\
\hline
\end{tabular}




\section{Table 1 Genetic complement for PG remodelling enzymes in 19 mycobacterial species (Continued)}

\begin{tabular}{|c|c|c|c|c|c|c|c|c|c|c|c|c|c|c|c|c|c|c|c|}
\hline $1 d t_{M+4}$ & Rv0192 & MRA_0200 & MT0202 & MAF_01930 & Mb0198 & BCG_0229 & MAV_4986 & MAР3634 & OCU_48990 & MUL_1085 & MMAR_0435 & MAB_4537c & MSMEG_0233 & $\begin{array}{l}\text { Mvan_3694 } \\
\text { Mvan_0177 }\end{array}$ & Mmcs_0151 & $\begin{array}{l}\text { Mkms_5680 } \\
\text { Mkms_0160 }\end{array}$ & $\begin{array}{l}\text { Mjls_4535 } \\
\text { Mjls_0141 }\end{array}$ & $\begin{array}{l}\text { Mflv55330 } \\
\text { Mflv2824 } \\
\text { Mflv55369 } \\
\text { Mflv_0479 }\end{array}$ & - \\
\hline $1 d t_{M t 5}$ & Rv0483 & MRA_0490 & MT0501 & MAF_04870 & Mb0493 & BCG_0524 & MAV_4666 & MAР3976 & OCU_45320 & MUL_4553 & MMAR_0809 & MAB_4061c & MSMEG_0929 & Mvan_0824 & Mmcs_0654 & Mkms_0667 & Mjls_0647 & Mflv_0089 & ML2446 \\
\hline \multicolumn{20}{|l|}{ Amidases } \\
\hline amil & Rv3717 & MRA_3754 & МТ3820 & MAF_37260 & Mb3744 & BCG_3777 & MAV_0385 & MAP0318 & OCU_03450 & MUL__308 & MMAR_5233 & MAB_0318c & MSMEG_6281 & Mvan_5529 & Mmcs_4905 & Mkms_4994 & Mjls_5273 & Mflv_1286 & ML2331 \\
\hline ami2 & Rv3915 & MRA_3954 & MT4034 & MAF_39300 & Mb3946 & BCG_0021 & MAV_5303 & MAP4341 & OCU_51370 & MUL_5068 & MMAR_5479 & MAB_4942 & MSMEG_6935 & Mvan_6069 & Mmcs_5404 & Mkms_5493 & Mjls_5780 & Mflv_0837 & ML2704 \\
\hline amis & Rv3811 & MRA_3851 & MT3918 & MAF_38260 & Mb3841 & BCG_3873 & MAV_0206 & MAP0209C & OCU_02160 & MUL_4995 & MMAR_5375 & MAB_0168c & MSMEG_6406 & Mvan_5652 & Mmcs_5022 & Mkms_5110 & Mjls_5403 & Mflv_1157 & - \\
\hline ami4 & Rv3594 & MRA_3633 & MT3700 & MAF_36070 & Mb3625 & BCG_3659 & - & - & - & - & - & MAB_4807 & MSMEG_5315 & Mvan_3376 & Mmcs_4180 & Mkms_4246 & Mjls_4402 & Mflv_3152 & - \\
\hline
\end{tabular}

The names of the various organisms analysed are shown in the columns and gene complement is given in the corresponding rows. Mycobacteria are grouped as M. tuberculosis Cluster (MTBC), other pathogens,

environmental species and $M$. leprae. Genes are sorted by functional groups in rows. The listing of a gene is based on its presence by protein BLAST analysis, either at curated sites or directly at NCBI. For all genes the protein sequence, in FASTA format, was obtained and utilised for phylogeny. Annotations for M. africanum (MAF_) and M. intracellulare (OCU_) were obtained directly from NCBI. BLAST analysis was performed against individual strains at NCBI using M. tuberculosis H37Rv homologues as the query sequence. The cut off was taken at a coverage of $>90 \%$ and an identity of $>40 \%$. MSMEG_1900 was identified at SmegmaList. In the case of ripD, parentheses indicate the 63C-terminal amino acid truncation. Further in-depth information, and confirmation of gene annotation, was obtained by assessment of phylogeny based on protein sequences, Additional file 1 Figure S1-S7. Font differences in the M. tuberculosis H37Rv column indicate genes that have been annotated as essential by two different TraSH analyses - indicated in bold (Sassetti et al. [20]) and/or italicised (Griffin et al. [21]) are those genes identified as essential or required for optimal growth. 


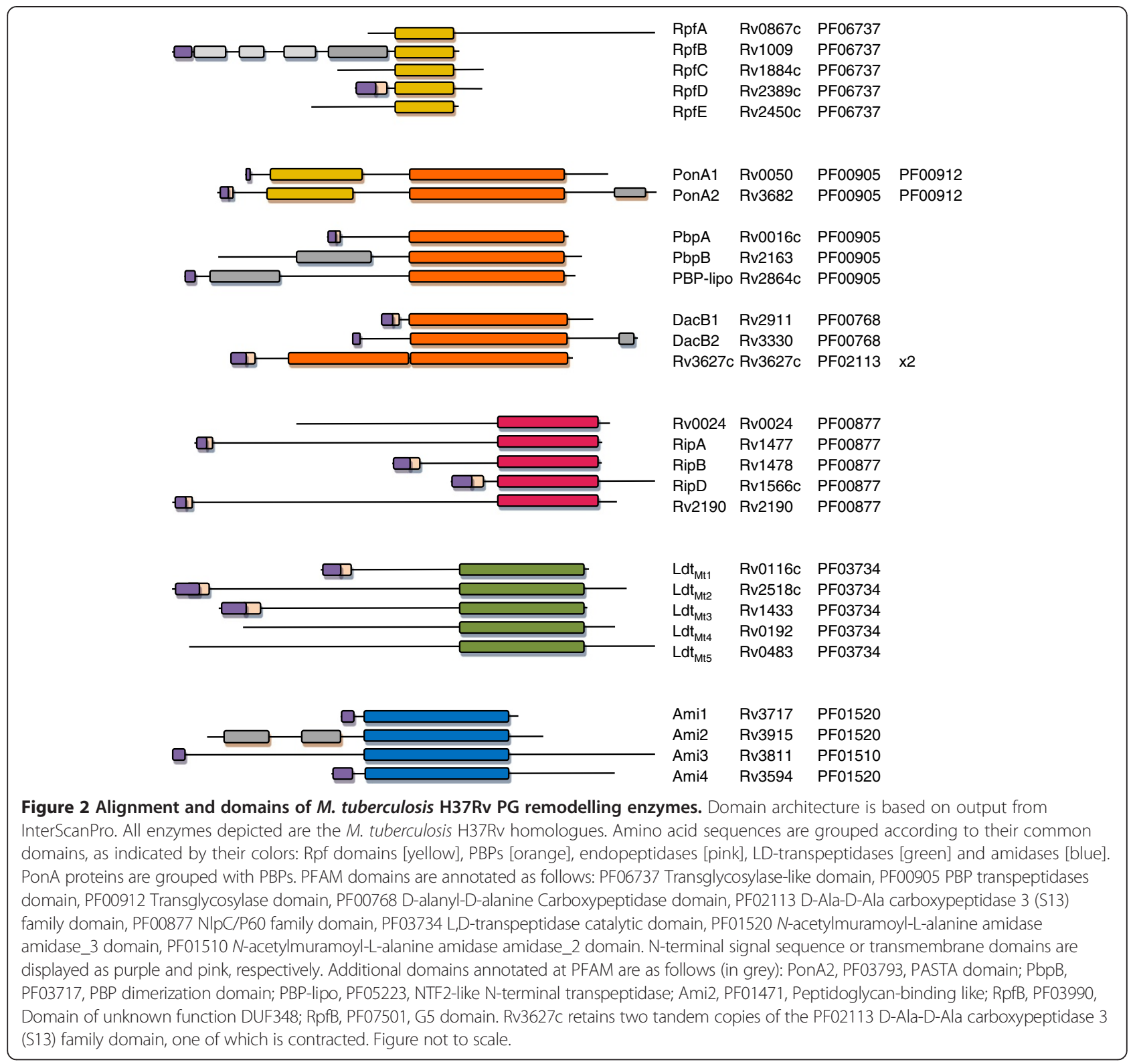

sp. KMS, Mycobacterium sp. MCS) and rpfE], Table 1 and Additional file 1: Figure S1. Although $r p f C$ (Rv1884c in $M$. tuberculosis) homologues have been annotated as present in all mycobacteria [45], our analysis shows that the $M$. tuberculosis rpfC homologue is absent from environmental species. Artemis Comparison Tool (ACT) whole genome alignment reveals that the region encoding $r p f C$ in $M$. tuberculosis is absent in M. smegmatis and all other environmental mycobacteria (data not shown). Thus, based on gene synteny, there is no direct $r p f C$ homologue in these strains. However, there is a local duplication of rpfE in all the environmental strains (annotated as MSMEG_4643 in M. smegmatis), Table 1, Additional file 1: Figure S1. Consequently, we re-annotate MSMEG_4640 to rpfE2, as a homologue of MSMEG_4643, rather than a homologue of
Rv1884c. As RpfE interacts with the Rpf Interacting Protein A (RipA) [46], there may be some functional consequence to the presence of multiple copies in M. smegmatis and other environmental bacteria.

The restriction of $r p f C$ and $r p f D$ homologues to pathogenic and MTBC strains, along with the duplication of $r p f B$ in some environmental species, raises interesting questions regarding the nature of growth stimulation in these organisms. These differences suggest that the latter require fewer secreted Rpfs and are more reliant on the membrane bound RpfB homologue. This could be related to the fact that environmental organisms are required to grow in diverse niches of varying size and complexity making them more dependent on localised growth stimulatory activity through a membrane bound 
Rpf rather than paracrine signalling from diffusible Rpfs produced by neighbouring organisms. It is noteworthy that of all five homologues in $M$. tuberculosis, deletion of $r p f B$ individually or in combination with $r p f A$ results in colony forming defects and prolonged time to reactivation from chronic infection in mice $[21,34,35]$.

The role of Rpfs in TB disease in humans remains enigmatic. It has been demonstrated that sputum from patients with active TB disease, before the initiation of treatment, is characterised by a population of dormant bacteria that require Rpfs for growth [47]. These data provide tantalizing preliminary evidence that Rpfs play an important role in determining bacterial population dynamics in TB infected patients and moreover are critical for disease transmission. Within the granulomatous environment, it may be preferable for the bacterial population as a whole to facilitate emergence of fitter clones which are able to exit from arrested growth. This could explain clonal emergence in clinical samples if few strains are able to expand sufficiently to cause tubercular lung disease.

\section{Penicillin binding proteins}

Penicillin Binding proteins (PBPs) are a large family of evolutionarily related cell wall associated enzymes, that bind $\beta$-lactam antibiotics $[48,49]$. PBPs are classified according to their molecular weight as either high molecular mass (HMM) or low molecular mass (LMM) and are broken down into Class A, Class B and Class C [49]. In mycobacteria, Class A PBPs constitute bi-functional enzymes designated as ponA1 (PBP1, Rv0050, [50]); and ponA2 (PBP1A, Rv3682 [51]), Figure 2. They contain separate domains for transpeptidase and transglycosylase activities. Both these genes are present in all mycobacteria and, as previously reported for M. smegmatis and other environmental strains, there is a duplication of ponA2 which was annotated as ponA3 [51], Table 1 and Additional file 1: Figure S2.

Class B PBP proteins PbpA ( $p b p A$; Rv0016c, [52]), $\mathrm{PbpB}$ ( $p b p B$; Rv2163c, [53]) and PBP-lipo (Rv2864c, [49]) are predicted to contain only transpeptidase domains and possibly additional dimerisation domains, but lack transglycosylase activities, Figure 2. Both $\mathrm{PbpA}$ and $\mathrm{PbpB}$ (FtsI) are involved in progression to cell division in M. smegmatis where gene deletion or depletion manifests in altered cell morphology and antibiotic resistance profiles [52]. In this family of PBPs - as exemplified by ponA2 - there is a distal duplication of PBP-lipo in the environmental strains, Table 1 and Additional file 1 : Figure S3. No experimental data on this are currently available, but the lipophilic domain is speculated to allow for cell wall association.

D,D-carboxypeptidases (DD-CPases) are designated as Class C PBPs and are generally present in high abundance
[54]. DD-CPases remove the D-Ala residue at position 5 of pentapeptides [8] and through this activity prevent cross linking of the stem peptide into $4 \rightarrow 3$ bridges, Figure 1. In mycobacteria, the dacB2-encoded DD-CPase is not affected by penicillin - though it does bind the antibiotic [55]. Inhibition of $\mathrm{DacB}$ through treatment with meropenem results in the accumulation of pentapeptides in $M$. tuberculosis [56]. In this context, DD-CPases have been implicated in regulating the amount of cross-linking that can occur within the PG sacculus [8]. Our analysis shows that $M$. tuberculosis H37Rv encodes three distinct DD-CPase homologues: dacB1 (Rv3330), dacB2 (Rv2911) and Rv3627c, Table 1, Figure 2 and Additional file 1: Figure S4. Rv3627c carries two PF02113 domains, one of which is contracted. In the environmental species there is a local duplication of the dacB2 (Rv2911) homologue, leading to consecutive numbering of the resulting duplicated genes for example, MSMEG_2432 and MSMEG_2433 in M. smegmatis. In addition, a distant DD-CPase homologue (annotated as MSMEG_1900 in M. smegmatis) was identified in the environmental strains, as well as in M. abscessus but not in the other pathogenic mycobacteria and MTBC, Table 1. Two additional loci - Rv0907 and Rv1367c - were identified in M. tuberculosis by in silico analysis through their predicted ß-lactamase domains and are grouped among Class C PBPs [49]. Analysis of these proteins revealed that they retain a $\beta$-lactamase binding domain (of the AmpH family) but further classification into the functional classes studied herein proved difficult. Consequently, we have not analysed these genes further.

\section{Endopeptidases}

Endopeptidases are enzymes that cleave within the stem peptides in PG. In this study, we focus on the Nlp/P60 class of endopeptidases, which cleave within the stem peptides between positions 2 and 3 as exemplified by RipA, Figure 1. RipA is an essential PG hydrolytic enzyme that synergistically interacts with $\mathrm{RpfB}$ and RpfE $[46,57]$ to form a complex that is able to degrade PG. The RipA-RpfB hydrolytic complex is negatively regulated by PonA2 [58] suggesting a dynamic interplay between PG hydrolases, one that would be significantly nuanced with the presence of multiple RipA and Rpf homologues. In this regard, our analysis reveals four endopeptidases in M. tuberculosis that display strong homology to ripA, Table 1, Figure 2, Additional file 1: Figure S5. With the exception of Mycobacterium abscessus and $M$. leprae, pathogenic mycobacteria retain all five of these homologues. Environmental strains display enhanced expansion of endopeptidases, with the exception of the ripD homologue (Rv1566c). The functional consequence of this remains unknown but it is noteworthy that these strains have also expanded their $r p f E$ and $r p f B$ gene repertoire, suggesting that the multiplicity in this 
case allows for a greater number of RipA-RpfB/E protein complexes, as well as for protein complexes with different subunit composition. Dysregulated expression of RipA leads to dramatic alterations in cellular morphology and growth [59] suggesting that careful regulation of this protein, both at the expression level as well as by post-translational level is essential. Genetic expansion of RipA homologues along with two copies of RpfB and RpfE, both of which interact with RipA implies a functional consequence of this expansion. In addition, strong regulation of these multiple copies would be required to prevent any detrimental effects on cell growth.

RipB displays strong sequence homology RipA in $M$. tuberculosis (100\% amino acid identity over 58\% coverage) and similar domain organization [60], but lacks the $\mathrm{N}$-terminal motif, Figure 2, that has been implicated in auto inhibition by blocking the active site in the threedimensional crystal structure [61]. More recently, high resolution crystal structures of RipB and the C-terminal module of RipA (designated as RipAc) revealed striking differences in the structure of these proteins, specifically in the $\mathrm{N}$-terminal fragments that cross the active site [60]. Both RipB and RipAc are able to bind high molecular weight PG and retain the ability to cleave PG with variable substrate specificity, which is not regulated by the presence of the $\mathrm{N}$-terminal domain [60]. This suggests that the $\mathrm{N}$-terminus does not regulate PG degrading activity and in this context, the physiological consequences of the reduced size of RipB and RipD, Figure 2, remain unknown. The high degree of conservation of RipB across all pathogenic mycobacteria including M. leprae, Table 1, Additional file 1: Figure S5 indicates that variable substrate specificity in PG hydrolases in essential for pathogenesis. The Mycobacterium marinum homologues of Rv1477 and Rv1478, iipA and iipB (MMAR_2284 and MMAR_2285 respectively), Table 1, Additional file 1: Figure S5, have been implicated in macrophage invasion, antibiotic susceptibility and cell division [62]. As with the other enzymes assessed in this study, environmental mycobacteria display greater genetic multiplicity for these homologues, Table 1.

Structural analysis of RipD reveals alterations in the catalytic domain, consistent with the inability of this protein to hydrolyse PG [63]. Nevertheless the core domain of RipD is able to bind mycobacterial PG and this binding is negatively regulated by the $\mathrm{C}$-terminal region [63]. However, RipD homologues in the environmental mycobacteria lack the 63C-terminal amino acids, Table 1 (shown in parentheses), possibly allowing for stronger binding of this enzyme to PG.

Rv2190c encodes another NlpC/P60-type PG hydrolase in mycobacteria. Deletion of this gene in $M$. tuberculosis results in altered colony morphology, attenuated growth in vitro, defective PDIM production and reduced colonisation of mouse lungs in the murine model of TB infection [64]. Consistent with this, homologues of Rv2190c are found in all pathogenic mycobacteria, Table 1, with notable genetic expansion in some environmental species. In contrast, the Rv0024 is absent from environmental species, suggesting that it could be required for intracellular growth or some other component of the pathogenic process, Table 1, Additional file 1: Figure S5.

\section{L,D - Transpeptidases}

L,D-transpeptidases (Ldt) are a group of carbapenem sensitive enzymes in $M$. tuberculosis [56] that contribute to the formation of a $3 \rightarrow 3$ link between the two adjacent mDAP ( $\mathrm{mDap} \rightarrow \mathrm{mDap}$ bridges) residues in PG, distinct from the classic $4 \rightarrow 3$ link (D-Ala $\rightarrow$ mDAP), Figure 1. $M$. abscessus [65] and M. tuberculosis [66] exhibit increased ratios of the $3 \rightarrow 3$ cross-link in stationary axenic culture, indicating that mycobacteria are capable of modulating their PG at the level of transpeptidation in response to growth stage and the availability of nutrients. Both Ldt $\mathrm{Mt1}_{1}$ and $\mathrm{Ldt}_{\mathrm{Mt} 2}$ (Rv0116c and Rv2518c respectively) were experimentally shown to affect $M$. tuberculosis H37Rv morphology, growth characteristics and antibiotic susceptibility in vivo [67]. The crystal structure of $\mathrm{Ldt}_{\mathrm{Mt} 2}$ places the extramembrane domain $80-100 \AA$ from the membrane surface and indicates that this enzyme is able to remodel PG within this spatial region of the PG sacculus [68]. More recently, it has been demonstrated that the combinatorial loss of both $\mathrm{Ldt}_{\mathrm{Mt} 1}$ and $\mathrm{Ldt}_{\mathrm{Mt} 2}$ in $M$. tuberculosis resulted in morphological defects and altered virulence in the murine model of TB infection [69]. A notable variability of L,D-transpeptidase genes is found in mycobacteria, Table 1, Figure 2 and Additional file 1: Figure S6. Five homologues are present in all but one pathogenic strain, while multiple homologues are evident in most environmental strains. The exception is $l d t_{M t 3}$ (Rv1433), which is absent from the pathogen Mycobacterium ulcerans and from the environmental species Mycobacterium vanbaalenii, $M$ sp. MCS and $M$. sp. KMS, yet its presence in $M$. leprae suggests functional importance. As with RipA, M. gilvum shows the greatest expansion of the $l d t$ genes. Biochemical characterisation of all five $M$. tuberculosis $\mathrm{H} 37 \mathrm{Rv}$ homologues, $\mathrm{Ldt}_{\mathrm{Mt} 1}-\mathrm{Ldt}_{\mathrm{Mt} 5}$, confirms PG cross-linking and/or ß-lactam acylating enzyme activities in all of these enzymes [70]. This activity can be abolished by treatment with imipenem and cephalosporins, indicating that this group of enzymes holds great promise for TB drug development [70,71]. Moreover, the functionality of all the Ldt homologues present in M. tuberculosis raises interesting questions with respect to the functional consequences of the expansion of this protein family in environmental strains, which may require greater flexibility in Ldt function. 


\section{Amidases}

While endopeptidases and transpeptidases are responsible for cleavage within or between peptide stems, amidases act to remove the entire peptide stem from the glycan strands, cleaving between the NA/GM moiety and the L-Ala in the first position of the stem peptide, Figure 1. The amidases have been implicated in PG degradation, antibiotic resistance/tolerance and cell separation in Escherichia coli and other organisms, and can be organised into 2 main families containing either an amidase_2 or amidase_3 - type domain [8,9,72]. The amidases of $E$. coli (which retains 5 amidases designated AmiA, AmiB, AmiC, AmiD and AmpD) have specific substrate requirements governed by the structural confirmation of the NAM carbohydrate moiety. Knockout of these amidases results in chaining phenotypes, abnormal cell morphologies and/or increased susceptibility to certain antibiotics [72-74]. Amidases have also been implicated in spore formation, germination and cell communication in Bacillus subtilis [75,76]. The role of amidases in mycobacterial growth, virulence and resuscitation from dormancy is unknown and any impact of these on mycobacterial morphology and antibiotic resistance remains to be demonstrated. Analysis of the amidase gene complement in mycobacteria reveals the presence of four homologues in $M$. tuberculosis, two containing the amidase_2 domain (ami3; Rv3811 and ami4; Rv3594) and two the amidase_3 domain (ami1; Rv3717 and ami2; Rv3915), Table 1, Figure 2 and Additional file 1: Figure S7. The crystal structure of Rv3717 from $M$. tuberculosis confirms that this enzyme is able to bind and cleave muramyl dipeptide [77]. The amidase family distinguishes itself from all other enzyme families by absence of a homologue (ami4) from nonMTBC pathogens and its presence in the MTBC and environmental strains. $M$. leprae retains only the ami1 and ami2 genes - both containing the amidase_3 domain. This suggests that amidase_2 domain amidase activity is dispensable specifically in this species, but required for peptidoglycan remodelling in the other pathogenic mycobacteria.

\section{Mycobacterium leprae}

Very little is known about in vitro growth and division of $M$. leprae, as it can only be grown in animal models. From our analysis, it is apparent that $M$. leprae habours notable genetic redundancy for PG remodelling enzymes (Table 1) in contrast to its minimal gene set for other areas of metabolism [78]. Considering that PG subunits or precursors cannot be scavenged from the host, it is expected that pathogenic bacteria would retain complete pathways for biosynthesis and remodelling of PG. However, the presence in $M$. leprae of multiple homologues within each class of PG remodelling enzyme assessed in this study, suggests that some level of multiplicity is required to ensure substrate flexibility. Further work in this regard is difficult due to the limited tractability of M. leprae for in vitro manipulation.

\section{Conclusions}

Mycobacteria represent a wide range of species with a great variety of phenotypes. Exposure to stresses which they encounter at various stages of their life cycles demands the ability to adapt. Consistent with this, many mycobacteria encode a multiplicity of genes for numerous important pathways such as respiration and cofactor biosynthesis $[79,80]$, which allows for a more nuanced regulation of physiology. The analysis performed herein summarises the general distribution of PG remodelling genes in diverse strains and reveals an emerging trend towards gene multiplicity in environmental mycobacteria. There is great conservation within the MTBC and other pathogenic mycobacteria. Of all strains, M. gilvum displays the greatest degree of gene expansion, containing a total 44 PG remodelling genes, Table 1 . This organism has not been studied extensively but may represent a potential model system for understanding how the genetic multiplicity for PG remodelling enzymes contributes to bacterial physiology. As expected $M$. leprae shows a reduction in the number of genes that encode the enzymes assessed in this study but still retains more than one representative of each functional class. This, together with the striking degree of conservation in some families of PG remodelling enzymes in pathogenic mycobacteria, suggests that PG biosynthesis, remodelling and possibly recycling are all potential vulnerable pathways for drug development. The extracellular nature of these enzymes provides an added advantage for drug screening since small molecules need not enter the cell for biological activity. Entry of compounds into mycobacterial cells remains the major confounding factor in current drug development initiatives. Moreover, the lack of human counterparts would ensure a high degree of specificity. In conclusion, the gene complements for PG remodelling revealed in this study most likely reflect the differential requirements of various mycobacteria for murein expansion/turnover during colonisation of and proliferation within host organisms or environmental niches.

\section{Methods}

The 19 mycobacterial strain sequences used in this study were all complete and either published [24,78,81-90] or directly submitted to GenBank [91] (Additional file 2: Table S1). The following sites were utilized for analysis of the genomes (Additional file 2: Table S2): The comparative genomic profile for the enzymes of interest were initiated by homology searches of known M. tuberculosis H37Rv genes at TubercuList [92], GenoList [93] or TBDB [94]. 
Where necessary for further analysis direct BLAST analysis was performed at NCBI [95], utilising protein sequence for BLASTp or DNA sequence for BLASTn particularly for the analysis of Mycobacterium sp. JLS, $M$. africanum and $M$. intracellulare which are not or only partially annotated at TBDB. To confirm the absence of genes, protein sequence was used for tBLASTn analysis. Additional homologues that are absent from $M$. tuberculosis H37Rv were identified by advanced search at SmegmaList (Mycobrowser) [96]. Where information was required for sequence level analysis, the Sanger Artemis Comparison Tool (ACT) [97] was utilized on annotated sequences obtained from the Integrated Microbial Genomes (IMG) site at the DOE Joint Genome Institute [98]. Phylogeny was established from FASTA files from all genes in Table 1 at EMBL-EBI by ClustalO [99] alignment and ClustalW2 [100] analysis and visualized using FigTree V1.4 software (http://tree.bio.ed.ac.uk/software/figtree). Functional annotation of each of the $M$. tuberculosis proteins was identified at InterScanPro [101], for PFAM domains [102], signal sequences (SignalP) [103] and membrane anchoring domains (TMHMM) [104].

\section{Additional files}

Additional file 1: Figure S1. Phylogenetic relationship between Resuscitation Promoting Factors from various mycobacteria. Figure S2. Phylogenetic relationship between Class A penicillin binding proteins (PonA family) from various mycobacteria. Figure S3. Phylogenetic relationship between Class B penicillin binding proteins (Pbp family) from various mycobacteria. Figure S4. Phylogenetic relationship between Class C penicillin binding proteins (DD-carboxypeptidases) from various mycobacteria. Figure S5. Phylogenetic relationship between endopeptidases (N/p/P60 - domain containing proteins) from various mycobacteria. Figure S6. Phylogenetic relationship between L,D-transpeptidases from various mycobacteria. Figure S7. Phylogenetic relationship between $\mathrm{N}$-acetylmuramoyl-L-alanine from various mycobacteria.

Additional file 2: Table S1. Mycobacterial strains included in this study. Table S2. Bioinformatics sites used for analysis.

\section{Competing interests}

The authors declare that they have no competing interests.

\section{Authors' contributions}

BDK conceived and designed the study. EEM conducted all the bioinformatics analyses and compiled the manuscript. SS and CE provided intellectual input on certain aspects of the study. All authors approve of the final content in the manuscript.

\footnotetext{
Acknowledgements

This work was supported by grants from the South African National Research Foundation (NRF), the Medical Research Council, the Department of Science and Technology. BK was supported by an Early Career Scientist award from the Howard Hughes Medical Institute. C.S.E was supported by postdoctoral fellowships from the NRF and the Centre of Aids Programme Research in South Africa (CAPRISA).
}

Received: 27 December 2013 Accepted: 12 March 2014 Published: 24 March 2014

\section{References}

1. Nikaido $\mathrm{H}$, Jarlier V: Permeability of the mycobacterial cell wall. Res Microbiol 1991, 142(4):437-443.

2. Chatterjee D: The mycobacterial cell wall: structure, biosynthesis and sites of drug action. Curr Opin Chem Biol 1997, 1(4):579-588.

3. Brennan PJ, Besra GS: Structure, function and biogenesis of the mycobacterial cell wall. Biochem Soc Trans 1997, 25(1):188-194.

4. Jarlier $\mathrm{V}$, Nikaido H: Mycobacterial cell wall: structure and role in natural resistance to antibiotics. FEMS Microbiol Lett 1994, 123(1-2):11-18.

5. Barry CE 3rd, Mdluli K: Drug sensitivity and environmental adaptation of mycobacterial cell wall components. Trends Microbiol 1996, 4(7):275-281.

6. Favrot $L$, Ronning DR: Targeting the mycobacterial envelope for tuberculosis drug development. Expert Rev Anti Infect Ther 2012, 10(9):1023-1036.

7. Typas A, Banzhaf M, Gross CA, Vollmer W: From the regulation of peptidoglycan synthesis to bacterial growth and morphology. Nat Rev Microbiol 2012, 10(2):123-136.

8. Vollmer W, Blanot D, de Pedro MA: Peptidoglycan structure and architecture. FEMS Microbiol Rev 2008, 32(2):149-167.

9. Vollmer W, Joris B, Charlier P, Foster S: Bacterial peptidoglycan (murein) hydrolases. FEMS Microbiol Rev 2008, 32(2):259-286.

10. Boneca IG: The role of peptidoglycan in pathogenesis. Curr Opin Microbiol 2005, 8(1):46-53

11. Kaur D, Guerin ME, Skovierova H, Brennan PJ, Jackson M: Chapter 2: Biogenesis of the cell wall and other glycoconjugates of Mycobacterium tuberculosis. Adv Appl Microbiol 2009, 69:23-78.

12. Besra GS, Brennan PJ: The mycobacterial cell wall: biosynthesis of arabinogalactan and lipoarabinomannan. Biochem Soc Trans 1997, 25(3):845-850.

13. Mahapatra S, Crick DC, McNeil MR, Brennan PJ: Unique structural features of the peptidoglycan of Mycobacterium leprae. J Bacterio/ 2008, 190(2):655-661.

14. Raymond JB, Mahapatra S, Crick DC, Pavelka MS Jr: Identification of the namH gene, encoding the hydroxylase responsible for the $\mathrm{N}$-glycolylation of the mycobacterial peptidoglycan. J Biol Chem 2005, 280(1):326-333.

15. Coulombe F, Divangahi M, Veyrier F, de Leseleuc L, Gleason JL, Yang Y, Kelliher MA, Pandey AK, Sassetti CM, Reed MB, Behr MA: Increased NOD2mediated recognition of $\mathrm{N}$-glycolyl muramyl dipeptide. J Exp Med 2009, 206(8):1709-1716.

16. Hansen JM, Golchin SA, Veyrier FJ, Domenech P, Boneca IG, Azad AK, Rajaram MV, Schlesinger LS, Divangahi M, Reed MB, Behr MA: $\mathrm{N}$-Glycolylated Peptidoglycan Contributes to the Immunogenicity but Not Pathogenicity of Mycobacterium tuberculosis. I Infect Dis 2013, 209(7):1045-1054.

17. Desmarais SM, De Pedro MA, Cava F, Huang KC: Peptidoglycan at its peaks: how chromatographic analyses can reveal bacterial cell wall structure and assembly. Mol Microbiol 2013, 89(1):1-13.

18. Zumla A, Nahid P, Cole ST: Advances in the development of new tuberculosis drugs and treatment regimens. Nat Rev Drug Discov 2013, 12(5):388-404.

19. Boshoff HI, Barry CE 3rd: Is the mycobacterial cell wall a hopeless drug target for latent tuberculosis? Drug Discovery Today: Disease Mechanisms 2006, 3(2):237-245.

20. Sassetti CM, Boyd DH, Rubin EJ: Genes required for mycobacterial growth defined by high density mutagenesis. Mol Microbiol 2003, 48(1):77-84.

21. Griffin JE, Gawronski JD, Dejesus MA, loerger TR, Akerley BJ, Sassetti CM: Highresolution phenotypic profiling defines genes essential for mycobacterial growth and cholesterol catabolism. PLoS Pathog 2011, 7(9):e1002251.

22. Mukamolova GV, Kaprelyants AS, Young DI, Young M, Kell DB: A bacterial cytokine. Proc Natl Acad Sci U S A 1998, 95(15):8916-8921.

23. Mukamolova GV, Murzin AG, Salina EG, Demina GR, Kell DB, Kaprelyants AS, Young M: Muralytic activity of Micrococcus luteus Rpf and its relationship to physiological activity in promoting bacterial growth and resuscitation. Mol Microbiol 2006, 59(1):84-98.

24. Cole ST, Brosch R, Parkhill J, Garnier T, Churcher C, Harris D, Gordon SV, Eiglmeier K, Gas S, Barry CE 3rd, Tekaia F, Badcock K, Basham D, Brown D, Chillingworth T, Connor R, Davies R, Devlin K, Feltwell T, Gentles S, Hamlin N, Holroyd S, Hornsby T, Jagels K, Krogh A, McLean J, Moule S, Murphy L, Oliver K, Osborne J, et al: Deciphering the biology of Mycobacterium tuberculosis from the complete genome sequence. Nature 1998, 393 (6685):537-544.

25. Kana BD, Mizrahi V: Resuscitation-promoting factors as lytic enzymes for bacterial growth and signaling. FEMS Immunol Med Microbiol 2009, 58(1):39-50. 
26. Mukamolova GV, Turapov OA, Young DI, Kaprelyants AS, Kell DB, Young M: A family of autocrine growth factors in Mycobacterium tuberculosis. Mol Microbiol 2002, 46(3):623-635

27. Kana BD, Mizrahi V: Resuscitation promoting factors in bacterial population dynamics during TB infection. Drug Discovery Today: Disease Mechanisms 2010, 7:e13-e18.

28. Keep NH, Ward JM, Cohen-Gonsaud M, Henderson B: Wake up! Peptidoglycan lysis and bacterial non-growth states. Trends Microbiol 2006, 14(6):271-276.

29. Keep NH, Ward JM, Robertson G, Cohen-Gonsaud M, Henderson B: Bacterial resuscitation factors: revival of viable but non-culturable bacteria. Cell Mol Life Sci 2006, 63(22):2555-2559.

30. Kell DB, Young M: Bacterial dormancy and culturability: the role of autocrine growth factors. Curr Opin Microbiol 2000, 3(3):238-243.

31. Tufariello JM, Chan J, Flynn JL: Latent tuberculosis: mechanisms of host and bacillus that contribute to persistent infection. Lancet Infect Dis 2003, 3(9):578-590.

32. Downing K, Mischenko W, Shleeva MO, Young DI, Young M, Kaprelyants AS, Apt AS, Mizrahi V: Mutants of Mycobacterium tuberculosis lacking three of the five $r p f$-like genes are defective for growth in vivo and for resuscitation in vitro. Infect Immun 2005, 73(5):3038-3043.

33. Kana BD, Gordhan BG, Downing KJ, Sung N, Vostroktunova G, Machowski EE, Tsenova L, Young M, Kaprelyants A, Kaplan G, Mizrahi V: The resuscitation-promoting factors of Mycobacterium tuberculosis are required for virulence and resuscitation from dormancy but are collectively dispensable for growth in vitro. Mol Microbiol 2008, 67(3):672-684.

34. Russell-Goldman E, Xu J, Wang X, Chan J, Tufariello JM: A Mycobacterium tuberculosis Rpf double-knockout strain exhibits profound defects in reactivation from chronic tuberculosis and innate immunity phenotypes. Infect Immun 2008, 76(9):4269-4281.

35. Tufariello JM, Mi K, Xu J, Manabe YC, Kesavan AK, Drumm J, Tanaka K, Jacobs WR Jr, Chan J: Deletion of the Mycobacterium tuberculosis resuscitationpromoting factor Rv1009 gene results in delayed reactivation from chronic tuberculosis. Infect Immun 2006, 74(5):2985-2995.

36. Gupta RK, Srivastava R: Resuscitation promoting factors: a family of microbial proteins in survival and resuscitation of dormant mycobacteria. Indian $\mathrm{J}$ Microbiol 2012, 52(2):114-121.

37. Haiser HJ, Yousef MR, Elliot MA: Cell wall hydrolases affect germination, vegetative growth, and sporulation in Streptomyces coelicolor. J Bacteriol 2009, 191(21):6501-6512.

38. Hett EC, Rubin EJ: Bacterial growth and cell division: a mycobacterial perspective. Microbiol Mol Biol Rev 2008, 72(1):126-156. table of contents.

39. Cohen-Gonsaud M, Barthe P, Bagneris C, Henderson B, Ward J, Roumestand $\mathrm{C}$, Keep $\mathrm{NH}$ : The structure of a resuscitation-promoting factor domain from Mycobacterium tuberculosis shows homology to lysozymes. Nat Struct Mol Biol 2005, 12(3):270-273.

40. Cohen-Gonsaud M, Keep NH, Davies AP, Ward J, Henderson B, Labesse G: Resuscitation-promoting factors possess a lysozyme-like domain. Trends Biochem Sci 2004, 29(1):7-10.

41. Ruggiero A, Tizzano B, Pedone E, Pedone C, Wilmanns M, Berisio R: Crystal structure of the resuscitation-promoting factor $\triangle D U F R p f B$ from $M$. tuberculosis. J Mol Biol 2009, 385(1):153-162.

42. Romano M, Aryan E, Korf H, Bruffaerts N, Franken CL, Ottenhoff TH, Huygen K: Potential of Mycobacterium tuberculosis resuscitation-promoting factors as antigens in novel tuberculosis sub-unit vaccines. Microbes Infect 2011, 14(1):86-95.

43. Riano F, Arroyo L, Paris S, Rojas M, Friggen AH, van Meijgaarden KE, Franken KL, Ottenhoff TH, Garcia LF, Barrera LF: T cell responses to DosR and Rpf proteins in actively and latently infected individuals from Colombia. Tuberculosis (Edinb) 2012, 92(2):148-159.

44. Kondratieva T, Rubakova E, Kana BD, Biketov S, Potapov V, Kaprelyants A, Apt A: Mycobacterium tuberculosis attenuated by multiple deletions of $r p f$ genes effectively protects mice against TB infection. Tuberculosis (Edinb) 2011, 91(3):219-223.

45. Ravagnani A, Finan $C L$, Young M: A novel firmicute protein family related to the actinobacterial resuscitation-promoting factors by nonorthologous domain displacement. BMC Genomics 2005, 6(1):39.

46. Hett EC, Chao MC, Deng LL, Rubin EJ: A mycobacterial enzyme essential for cell division synergizes with resuscitation-promoting factor. PLOS Pathog 2008, 4(2):e1000001.

47. Mukamolova GV, Turapov O, Malkin J, Woltmann G, Barer MR: Resuscitation-promoting factors reveal an occult population of tubercle bacilli in sputum. Am J Respir Crit Care Med 2009, 181(2):174-180.
48. Goffin C, Ghuysen JM: Multimodular penicillin-binding proteins: an enigmatic family of orthologs and paralogs. Microbiol Mol Biol Rev 1998, 62(4):1079-1093.

49. Sauvage E, Kerff F, Terrak M, Ayala JA, Charlier P: The penicillin-binding proteins: structure and role in peptidoglycan biosynthesis. FEMS Microbiol Rev 2008, 32(2):234-258.

50. Billman-Jacobe $\mathrm{H}$, Haites RE, Coppel RL: Characterization of a Mycobacterium smegmatis mutant lacking penicillin binding protein 1. Antimicrob Agents Chemother 1999, 43(12):3011-3013.

51. Patru MM, Pavelka MS Jr: A role for the class A penicillin-binding protein PonA2 in the survival of Mycobacterium smegmatis under conditions of nonreplication. J Bacteriol 2010, 192(12):3043-3054.

52. Dasgupta A, Datta P, Kundu M, Basu J: The serine/threonine kinase PknB of Mycobacterium tuberculosis phosphorylates PBPA, a penicillin-binding protein required for cell division. Microbiology 2006, 152(Pt 2):493-504.

53. Plocinski P, Ziolkiewicz M, Kiran M, Vadrevu SI, Nguyen HB, Hugonnet J, Veckerle C, Arthur M, Dziadek J, Cross TA, Madiraju M, Rajagopalan M: Characterization of $\mathrm{CrgA}$, a new partner of the Mycobacterium tuberculosis peptidoglycan polymerization complexes. J Bacteriol 2011 193(13):3246-3256.

54. Ghosh SS, Dakoji S, Tanaka Y, Cho YJ, Mobashery S: Properties of analogues of an intermediate in the process of mechanism-based inactivation of carboxypeptidase A. Bioorg Med Chem 1996, 4(9):1487-1492.

55. Bourai N, Jacobs WR Jr, Narayanan S: Deletion and overexpression studies on DacB2, a putative low molecular mass penicillin binding protein from Mycobacterium tuberculosis $\mathrm{H}_{37} \mathrm{Rv}$. Microb Pathog 2012, 52(2):109-116.

56. Kumar P, Arora K, Lloyd JR, Lee IY, Nair V, Fischer E, Boshoff HI, Barry CE 3rd: Meropenem inhibits D, D-carboxypeptidase activity in Mycobacterium tuberculosis. Mol Microbiol 2012, 86(2):367-381.

57. Hett EC, Chao MC, Steyn AJ, Fortune SM, Deng LL, Rubin EJ: A partner for the resuscitation-promoting factors of Mycobacterium tuberculosis. $\mathrm{Mol}$ Microbiol 2007, 66(3):658-668

58. Hett EC, Chao MC, Rubin EJ: Interaction and modulation of two antagonistic cell wall enzymes of mycobacteria. PLoS Pathog 2010, 6(7):e1001020.

59. Chao MC, Kieser KJ, Minami S, Mavrici D, Aldridge BB, Fortune SM, Alber T, Rubin EJ: Protein complexes and proteolytic activation of the cell wall hydrolase RipA regulate septal resolution in mycobacteria. PLoS Pathog 2013, 9(2):e1003197.

60. Both D, Schneider G, Schnell R: Peptidoglycan remodeling in Mycobacterium tuberculosis: comparison of structures and catalytic activities of RipA and RipB. J Mol Biol 2013, 413(1):247-260.

61. Ruggiero A, Marasco D, Squeglia F, Soldini S, Pedone E, Pedone C, Berisio R: Structure and functional regulation of RipA, a mycobacterial enzyme essential for daughter cell separation. Structure 2010, 18(9):1184-1190.

62. Gao LY, Pak M, Kish R, Kajihara K, Brown EJ: A mycobacterial operon essential for virulence in vivo and invasion and intracellular persistence in macrophages. Infect Immun 2006, 74(3):1757-1767.

63. Both D, Steiner EM, Izumi A, Schneider G, Schnell R: RipD (Rv1566c) from Mycobacterium tuberculosis: adaptation of an NIpC/p60 domain to a noncatalytic peptidoglycan-binding function. Biochem J 2013, 457(1):33-41

64. Parthasarathy G, Lun S, Guo H, Ammerman NC, Geiman DE, Bishai WR: Rv2190c, an NIpC/P60 family protein, is required for full virulence of Mycobacterium tuberculosis. PLoS One 2012, 7(8):e43429.

65. Lavollay M, Fourgeaud M, Herrmann JL, Dubost L, Marie A, Gutmann L, Arthur M, Mainardi JL: The peptidoglycan of Mycobacterium abscessus is predominantly cross-linked by L, D-transpeptidases. J Bacteriol 2011, 193(3):778-782.

66. Lavollay M, Arthur M, Fourgeaud M, Dubost L, Marie A, Veziris N, Blanot D, Gutmann L, Mainardi JL: The peptidoglycan of stationary-phase Mycobacterium tuberculosis predominantly contains cross-links generated by L, D-transpeptidation. J Bacterio/ 2008, 190(12):4360-4366.

67. Gupta R, Lavollay M, Mainardi JL, Arthur M, Bishai WR, Lamichhane G: The Mycobacterium tuberculosis protein $\mathrm{Ldt}_{\mathrm{Mt} 2}$ is a nonclassical transpeptidase required for virulence and resistance to amoxicillin. Nat Med 2010, 16(4):466-469.

68. Both D, Steiner EM, Stadler D, Lindqvist Y, Schnell R, Schneider G: Structure of LdtMt2, an L, D-transpeptidase from Mycobacterium tuberculosis. Acta Crystallogr D Biol Crystallogr 2013, 69(Pt 3):432-441.

69. Schoonmaker MK, Bishai WR, Lamichhane G: Non-classical transpeptidases of Mycobacterium tuberculosis alter cell size, morphology, cytosolic matrix, protein localization, virulence and resistance to beta-lactams. J Bacteriol 2014, 196(7):1394-1402. 
70. Cordillot M, Dubee V, Triboulet S, Dubost L, Marie A, Hugonnet JE, Arthur M, Mainardi JL: In vitro cross-linking of peptidoglycan by Mycobacterium tuberculosis L,D-transpeptidases and inactivation of these enzymes by carbapenems. Antimicrob Agents Chemother 2013, 57(12):5940-5945.

71. Dubee V, Triboulet S, Mainardi JL, Etheve-Quelquejeu M, Gutmann L, Marie A, Dubost L, Hugonnet JE, Arthur M: Inactivation of Mycobacterium tuberculosis L, D-transpeptidase LdtMt1 by carbapenems and cephalosporins. Antimicrob Agents Chemother 2012, 56(8):4189-4195.

72. Heidrich C, Templin MF, Ursinus A, Merdanovic M, Berger J, Schwarz H, de Pedro MA, Holtje JV: Involvement of $\mathrm{N}$-acetylmuramyl-L-alanine amidases in cell separation and antibiotic-induced autolysis of Escherichia coli. Mol Microbiol 2001, 41(1):167-178.

73. Korsak D, Liebscher S, Vollmer W: Susceptibility to antibiotics and betalactamase induction in murein hydrolase mutants of Escherichia coli. Antimicrob Agents Chemother 2005, 49(4):1404-1409.

74. Jacobs C, Joris B, Jamin M, Klarsov K, Van Beeumen J, Mengin-Lecreulx D van Heijenoort J, Park JT, Normark S, Frere JM: AmpD, essential for both beta-lactamase regulation and cell wall recycling, is a novel cytosolic $\mathrm{N}$-acetylmuramyl-L-alanine amidase. Mol Microbiol 1995, 15(3):553-559.

75. Popham DL, Helin J, Costello CE, Setlow P: Muramic lactam in peptidoglycan of Bacillus subtilis spores is required for spore outgrowth but not for spore dehydration or heat resistance. Proc Natl Acad Sci U S A 1996, 93(26):15405-15410.

76. Smith TJ, Blackman SA, Foster SJ: Autolysins of Bacillus subtilis: multiple enzymes with multiple functions. Microbiology 2000, 146(Pt 2):249-262

77. Prigozhin DM, Mavrici D, Huizar JP, Vansell HJ, Alber T: Structural and Biochemical Analyses of Mycobacterium tuberculosis N-Acetylmuramyl-Lalanine Amidase Rv3717 Point to a Role in Peptidoglycan Fragment Recycling. J Biol Chem 2013, 288(44):31549-31555.

78. Cole ST, Eiglmeier K, Parkhill J, James KD, Thomson NR, Wheeler PR, Honoré N, Garnier T, Churcher C, Harris D, Mungall K, Basham D, Brown D, Chillingworth T, Connor R, Davies RM, Devlin K, Duthoy S, Feltwell T, Fraser A, Hamlin N, Holroyd S, Hornsby T, Jagels K, Lacroix C, Maclean J, Moule S, Murphy L, Oliver K, Quail MA, et al: Massive gene decay in the leprosy bacillus. Nature 2001, 409(6823):1007-1011.

79. Kana D, Machowski E, Schechter N, Shin JT, Rubin H, Mizrahi V: Electron transport and respiration. In Mycobacterium: Genomics and Molecular Biology. Caister Academic Press: Norfolk, UK; 2009:35-64.

80. Williams MJ, Kana BD, Mizrahi V: Functional analysis of molybdopterin biosynthesis in mycobacteria identifies a fused molybdopterin synthase in Mycobacterium tuberculosis. J Bacteriol 2011, 193(1):98-106.

81. Bentley SD, Comas I, Bryant JM, Walker D, Smith NH, Harris SR, Thurston S, Gagneux S, Wood J, Antonio M, Quail MA, Gehre F, Adegbola RA, Parkhill J, de Jong BC: The genome of Mycobacterium africanum West African 2 reveals a lineage-specific locus and genome erosion common to the $M$. tuberculosis complex. PLoS Negl Trop Dis 2012, 6(2):e1552.

82. Brosch R, Gordon SV, Garnier T, Eiglmeier K, Frigui W, Valenti P, Dos Santos S, Duthoy S, Lacroix C, Garcia-Pelayo C, Inwald JK, Golby P, Garcia JN, Hewinson RG, Behr MA, Quail MA, Churcher C, Barrell BG, Parkhill J, Cole ST: Genome plasticity of BCG and impact on vaccine efficacy. Proc Natl Acad Sci U S A 2007, 104(13):5596-5601.

83. Fleischmann RD, Alland D, Eisen JA, Carpenter L, White O, Peterson J, DeBoy R, Dodson R, Gwinn M, Haft D, Hickey E, Kolonay JF, Nelson WC, Umayam LA, Ermolaeva M, Salzberg SL, Delcher A, Utterback T, Weidman J, Khouri H, Gill J, Mikula A, Bishai W, Jacobs Jr WR Jr, Venter JC, Fraser CM: Whole-genome comparison of Mycobacterium tuberculosis clinical and laboratory strains. J Bacteriol 2002, 184(19):5479-5490

84. Garnier T, Eiglmeier K, Camus JC, Medina N, Mansoor H, Pryor M, Duthoy S, Grondin S, Lacroix C, Monsempe C, Simon S, Harris B, Atkin R, Doggett J, Mayes R, Keating L, Wheeler PR, Parkhill J, Barrell BG, Cole ST, Gordon SV, Hewinson RG: The complete genome sequence of Mycobacterium bovis. Proc Natl Acad Sci U S A 2003, 100(13):7877-7882.

85. Kim BJ, Choi BS, Lim JS, Choi IY, Lee JH, Chun J, Kook YH, Kim BJ: Complete genome sequence of Mycobacterium intracellulare strain ATCC 13950(T). J Bacteriol 2012, 194(10):2750.

86. Li L, Bannantine JP, Zhang Q, Amonsin A, May BJ, Alt D, Banerji N, Kanjilal S, Kapur V: The complete genome sequence of Mycobacterium avium subspecies paratuberculosis. Proc Natl Acad Sci U S A 2005, 102(35):12344-12349.

87. Shallom SJ, Gardina PJ, Myers TG, Sebastian Y, Conville P, Calhoun LB, Tettelin H, Olivier KN, Uzel G, Sampaio EP, Holland SM, Zelazny AM: New Rapid Scheme for Distinguishing the Subspecies of the Mycobacterium abscessus Group and Identifying Mycobacterium massiliense Isolates with Inducible Clarithromycin Resistance. J Clin Microbiol 2013, 51(9):2943-2949.

88. Stinear TP, Seemann T, Harrison PF, Jenkin GA, Davies JK, Johnson PD, Abdellah Z, Arrowsmith C, Chillingworth T, Churcher C, Clarke K, Cronin A, Davis P, Goodhead I, Holroyd N, Jagels K, Lord A, Moule S, Mungall K, Norbertczak H, Quail MA, Rabbinowitsch E, Walker D, White B, Whitehead S, Small PL, Brosch R, Ramakrishnan L, Fischbach MA, Parkhill J, Cole ST: Insights from the complete genome sequence of Mycobacterium marinum on the evolution of Mycobacterium tuberculosis. Genome Res 2008, 18(5):729-741.

89. Stinear TP, Seemann T, Pidot S, Frigui W, Reysset G, Garnier T, Meurice G, Simon D, Bouchier C, Ma L, Tichit M, Porter JL, Ryan J, Johnson PD, Davies JK, Jenkin GA, Small PL, Jones LM, Tekaia F, Laval F, Daffé M, Parkhill J, Cole ST: Reductive evolution and niche adaptation inferred from the genome of Mycobacterium ulcerans, the causative agent of Buruli ulcer. Genome Res 2007, 17(2):192-200.

90. Zheng H, Lu L, Wang B, Pu S, Zhang X, Zhu G, Shi W, Zhang L, Wang H, Wang $S$, Zhao G, Zhang Y: Genetic basis of virulence attenuation revealed by comparative genomic analysis of Mycobacterium tuberculosis strain H37Ra versus H37Rv. PLoS One 2008, 3(6):e2375.

91. Benson DA, Cavanaugh M, Clark K, Karsch-Mizrachi I, Lipman DJ, Ostell J, Sayers EW: GenBank. Nucleic Acids Res 2013, 41(Database issue):D36-D42.

92. Cole ST: Learning from the genome sequence of Mycobacterium tuberculosis H37Rv. FEBS Lett 1999, 452(1-2):7-10.

93. Lechat P, Hummel L, Rousseau S, Moszer I: GenoList: an integrated environment for comparative analysis of microbial genomes. Nucleic Acids Res 2008, 36(Database issue):D469-D474.

94. Reddy TB, Riley R, Wymore F, Montgomery P, DeCaprio D, Engels R, Gellesch M, Hubble J, Jen D, Jin H, Koehrsen M, Larson L, Mao M, Nitzberg M, Sisk P, Stolte C, Weiner B, White J, Zachariah ZK, Sherlock G, Galagan JE, Ball CA, Schoolnik GK: TB database: an integrated platform for tuberculosis research. Nucleic Acids Res 2009, 37(Database issue):D499-D508.

95. Altschul SF, Gish W, Miller W, Myers EW, Lipman DJ: Basic local alignment search tool. J Mol Biol 1990, 215(3):403-410.

96. Kapopoulou A, Lew JM, Cole ST: The MycoBrowser portal: a comprehensive and manually annotated resource for mycobacterial genomes. Tuberculosis (Edinb) 2011, 91(1):8-13.

97. Carver TJ, Rutherford KM, Berriman M, Rajandream MA, Barrell BG, Parkhill J: ACT: the Artemis Comparison Tool. Bioinformatics 2005, 21(16):3422-3423.

98. Markowitz VM, Chen IM, Palaniappan K, Chu K, Szeto E, Grechkin Y, Ratner A Jacob B, Huang J, Williams P, Huntemann M, Anderson I, Mavromatis K, Ivanova NN, Kyrpides NC: IMG: the Integrated Microbial Genomes database and comparative analysis system. Nucleic Acids Res 2012, 40(Database issue):D115-D122.

99. Sievers F, Wilm A, Dineen D, Gibson TJ, Karplus K, Li W, Lopez R, McWilliam $H$, Remmert M, Soding J, Thompson JD, Higgins DG: Fast, scalable generation of high-quality protein multiple sequence alignments using Clustal Omega. Mol Syst Biol 2011, 7:539.

100. Larkin MA, Blackshields G, Brown NP, Chenna R, McGettigan PA, McWilliam H, Valentin F, Wallace IM, Wilm A, Lopez R, Thompson JD, Gibson TJ, Higgins DG: Clustal W and Clustal X version 2.0. Bioinformatics 2007, 23(21):2947-2948.

101. Quevillon E, Silventoinen V, Pillai S, Harte N, Mulder N, Apweiler R, Lopez R: InterProScan: protein domains identifier. Nucleic Acids Res 2005, 33(Web Server issue):W116-W120

102. Punta M, Coggill PC, Eberhardt RY, Mistry J, Tate J, Boursnell C, Pang N, Forslund K, Ceric G, Clements J, Heger A, Holm L, Sonnhammer EL, Eddy SR, Bateman A, Finn RD: The Pfam protein families database. Nucleic Acids Res 2012, 40(Database issue):D290-D301.

103. Petersen TN, Brunak S, von Heijne G, Nielsen H: SignalP 4.0: discriminating signal peptides from transmembrane regions. Nat Methods 2011, 8(10):785-786

104. Moller S, Croning MD, Apweiler R: Evaluation of methods for the prediction of membrane spanning regions. Bioinformatics 2001, 17(7):646-653.

\section{doi:10.1186/1471-2180-14-75}

Cite this article as: Machowski et al:: Comparative genomics for mycobacterial peptidoglycan remodelling enzymes reveals extensive genetic multiplicity. BMC Microbiology 2014 14:75. 